\title{
Reversine-treated fibroblasts acquire myogenic competence in vitro and in regenerating skeletal muscle
}

\author{
Luigi Anastasia ${ }^{1,6}$, Maurilio Sampaolesi ${ }^{2,3,6}$, Nadia Papini ${ }^{1}$, \\ Diego Oleari ${ }^{2}$, Giuseppe Lamorte ${ }^{2}$, Cristina Tringali ${ }^{1}$, Eugenio \\ Monti $^{4}$, Daniela Galli ${ }^{2}$, Guido Tettamanti ${ }^{1}$, Giulio $\operatorname{Cossu}^{\star, 2,5}$ and \\ Bruno Venerando, \\ 1 Department of Medical Chemistry, Biochemistry and Biotechnology, University \\ of Milan, L.I.T.A. via F.lli Cervi 93, 20090 Segrate, Milan, Italy \\ 2 Stem Cell Research Institute, H.S. Raffaele, via Olgettina 58, Milan 20132, \\ Italy \\ 3 Department of Experimental Medicine, University of Pavia, viale Forlanini 6, \\ Pavia 27100, Italy \\ ${ }^{4}$ Department of Biomedical Science and Biotechnology, University of Brescia, \\ viale Europa 11, Brescia 25123, Italy \\ 5 Institute of Cell Biology and Tissue Engineering, San Raffaele Biomedical Park \\ of Rome, via Castel Romano 100, Rome 00128, Italy \\ 6 These authors contributed equally to this work. \\ * Corresponding authors: B Venerando, Department of Medical Chemistry, \\ Biochemistry and Biotechnology, Faculty of Exercise Science, University of \\ Milan, Via F.lli Cervi 93, Segrate, Milan 20090, Italy. Tel: + 39(02)503-30361; \\ Fax: + 39(02)503-30365; \\ E-mail: bruno.venerando@unimi.it and \\ G Cossu, Stem Cell Research Institute, Dibit, H. San Raffaele, Via Olgettina \\ 58, 20132 Milan, Italy. \\ Tel: + 39(02)2643-4954; Fax: + 39(02)2643-4621; \\ E-mail: cossu.giulio@ hsr.it
}

Received 14.12.05; revised 01.3.06; accepted 05.4.06; published online 26.5.06 Edited by G Melino

\begin{abstract}
Stem cells hold a great potential for the regeneration of damaged tissues in cardiovascular or musculoskeletal diseases. Unfortunately, problems such as limited availability, control of cell fate, and allograft rejection need to be addressed before therapeutic applications may become feasible. Generation of multipotent progenitors from adult differentiated cells could be a very attractive alternative to the limited in vitro self-renewal of several types of stem cells. In this direction, a recently synthesized unnatural purine, named reversine, has been proposed to induce reversion of adult cells to a multipotent state, which could be then converted into other cell types under appropriate stimuli. Our study suggests that reversine treatment transforms primary murine and human dermal fibroblasts into myogenic-competent cells both in vitro and in vivo. Moreover, this is the first study to demonstrate that plasticity changes arise in primary mouse and human cells following reversine exposure.

Cell Death and Differentiation (2006) 13, 2042-2051.

doi:10.1038/sj.cdd.4401958; published online 26 May 2006
\end{abstract}

Keywords: reversine; transdifferentiation; muscle; regeneration

Abbreviations: ESC, embryonic stem cells; GFP, green fluorescent protein

\section{Introduction}

Stem cells $s^{1,2}$ attract an ever-increasing interest for their potential therapeutic use for many diseases, such as type I diabetes, muscular dystrophies, cancer, neurodegenerative, and cardiovascular disorders. ${ }^{3-5}$ In contrast with embryonic stem cells (ESCs), that nonetheless raise ethic controversy, the majority of human adult stem cells are difficult to expand in culture to the scale required for possible therapeutic applications without loss of pluripotency. In the past few years, several types of adult stem cells have been isolated from different sources and tested for their capability of rescuing the phenotype of several diseases, including muscular dystrophy. Among these, bone marrow-derived multipotent adult progenitors, ${ }^{6}$ vessel-associated mesoangioblasts, ${ }^{7}$ and side population (SP) bone marrow-isolated stem cells ${ }^{8}$ could be differentiated into myocytes both in vitro and in vivo with moderate efficiency. Unfortunately, some adult stem cells, such as hematopoietic stem cells, have a limited self-renewal ex vivo, ${ }^{9}$ whereas others, such as neural stem cells, are isolated with difficulty from human tissues. Moreover, cell rejection in heterologous cell therapy has been shown as a primary issue to be solved before stem cell therapy may become feasible. In this context, the possibility of reprogramming readily available adult cells into multipotent progenitors ${ }^{10}$ appears a promising alternative, although technically challenging. Within this scenario, Ding and coworkers, after some preliminary attempts by Schultz group,,$^{11,12}$ have recently synthesized ${ }^{13}$ an unnatural 2,6disubstituted purine, named reversine, that has been speculated to induce mouse myogenic cells $\mathrm{C} 2 \mathrm{C} 12$ to regress to multipotent progenitor cells, able to differentiate into osteoblasts and adipocytes under proper stimulation. The potential for applications of these challenging results faces the limitation that $\mathrm{C}_{2} \mathrm{C} 12$ are an immortal, aneuploid, and tumorigenic cell line. Moreover, $\mathrm{C} 2 \mathrm{C} 12$ cells have been shown to spontaneously differentiate into osteoblasts ${ }^{14}$ and adipocytes ${ }^{15}$ upon proper hormonal stimulation. ${ }^{16}$ Prompted by the possible new therapeutic perspective generated by these results, we decided to test reversine on readily accessible primary cells, that is, dermal fibroblasts. These cells are easily expandable in vitro and maintain normal phenotype and, more importantly, genetic stability. This model, if workable, would appear to be more robust and offers higher predictive ability towards in vivo counterparts and their response to compound effects.

Our study was initially directed to evaluate the effect of different doses of reversine on fibroblasts proliferation and expression of their tissue-specific markers. In a successive approach, we cocultured reversine-treated fibroblasts with myogenic $\mathrm{C} 2 \mathrm{C} 12$ cells, as a stimulus for differentiation, and evaluated their ability to differentiate into skeletal muscle cells. Then, we analyzed the ability of reversine-treated 
murine fibroblasts to differentiate in vivo after cell transplantation in mice tibialis anterior (TA) muscle, $24 \mathrm{~h}$ after a single injection of cardiotoxin that induces muscle regeneration. ${ }^{17}$

\section{Results}

\section{Effect of reversine on primary fibroblasts}

Dermal fibroblasts, isolated from transgenic mice expressing green fluorescent protein (GFP), were grown for 4 days in the presence of $5 \mu \mathrm{M}$ reversine in growth medium as reported by Ding's group for $\mathrm{C} 2 \mathrm{C} 12$ cells. ${ }^{13}$ This concentration appeared to be optimal in the range studied $(0.1-10 \mu \mathrm{M})$. Control cells were treated with the same volume of dimethylsulfoxide (DMSO) in which reversine was dissolved. After 4 days of reversine treatment, fibroblasts acquired a drastically different morphology (Figure 1b) compared to control cells (Figure 1a), appearing considerably larger in size (up to nine times compared to control cells), flatter, less contrasted, and more adhesive to the culture plate. Unexpectedly, GFP appeared to be localized in the peri-nuclear area (Figure 1b). After minor cell loss during the first day of reversine treatment $(30 \%)$, no significant cell death was observed, although growth inhibition was noticed, as confirmed by cell count (Figure 2a), XTT (tetrazolium salt) test ${ }^{18}$ (58\% proliferation reduction compared to control cells, data not shown) decrease of cyclin B expression, observed by reverse transcriptase-polymerase chain reaction (RT-PCR) analysis (Figure $2 b$ ). Moreover, cell cycle analysis by flow cytofluorimetry indicated the formation of a tetraploid cell population already after $3 \mathrm{~h}$ of treatment, reaching about $90 \%$ at the end of the treatment (Figure $2 \mathrm{c}$ ). Treated fibroblasts shifted from a diploid/mononuclear $(2 n)$ to a tetraploid/binuclear $(2 \times 2 n)$ population, possibly through an aborted cytokinesis (Figure $2 \mathrm{~d}$ ), as previously observed by Schultz's group with reversine analogs, ${ }^{19,20}$ and as it occurs in normal rat hepatocytes. ${ }^{21}$ Nevertheless, no significant cell death was observed, even beyond 8-10 days of treatment, showing that reversine treatment does not cause irreversible damage to cells. No significant changes in the mRNA levels of
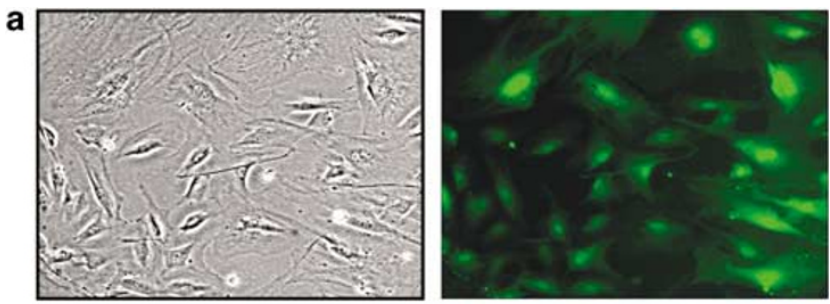

b
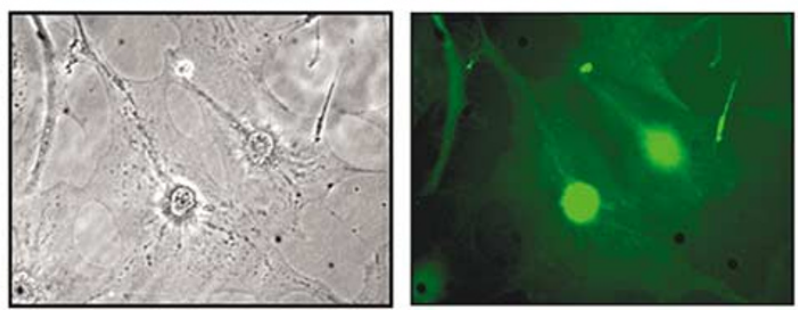

Figure 1 Effects of reversine on dermal fibroblasts. Phase-contrast and fluorescence microphotographs of GFP fibroblasts after (a) 4-day treatment with DMSO (control). (b) 4-day treatment with $5 \mu \mathrm{M}$ reversine cyclins A, D, and E, nor of p16, p21, and p27 could be detected by RT-PCR in both control and reversine-treated fibroblasts (data not shown). To assess whether reversine treatment alters the plasticity of fibroblasts, we evaluated the expression of fibroblast-specific marker HSP47. ${ }^{22}$ Reversine treatment caused a decrease of HSP47, which almost disappeared after 8 days (Figure $2 b$ ). Interestingly, upon reversine removal, fibroblasts gradually returned to their original phenotype and proliferation rate after 3 weeks in normal culture medium (Figure 2a), and both cyclin B and HSP47 mRNAs were restored (Figure $2 \mathrm{~b}$ ).

Despite evidence of alteration of differentiation status, that is, loss of HSP47 transcripts and altered phenotype, stem cell markers were not detected following exposure to reversine. Hematopoietic stem cell markers such as $\mathrm{CD}_{3}{ }^{23}$ and CD45, ${ }^{24}$ satellite cell markers such as PAX3 and PAX7, ${ }^{25}$ or mesenchymal markers such as $C D 73^{26}$ and $C D 105^{26}$ could not be detected by RT-PCR in treated cells (data not shown).

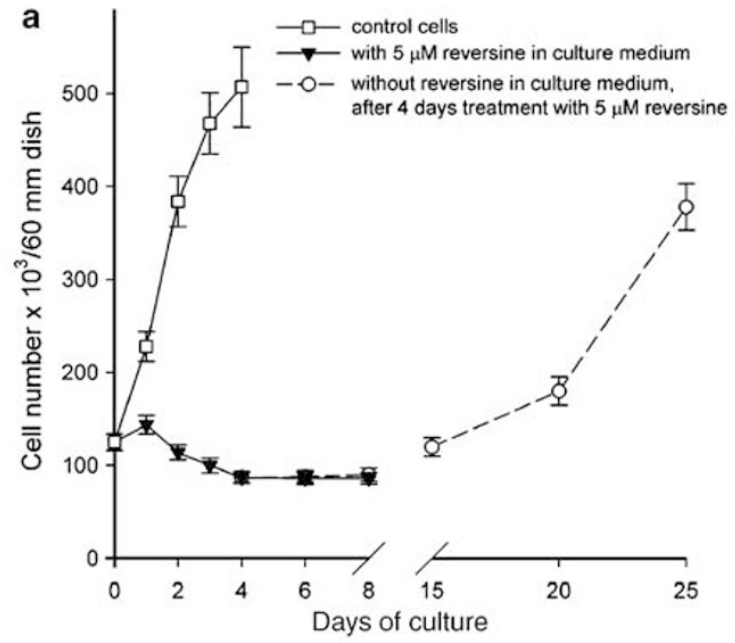

b
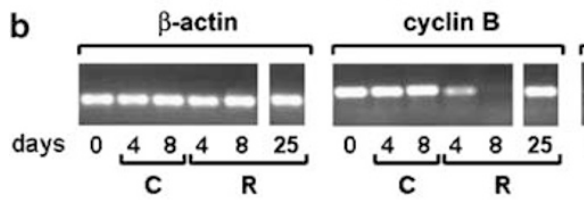

HSP 47
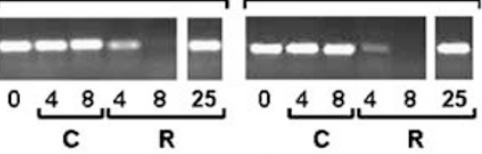

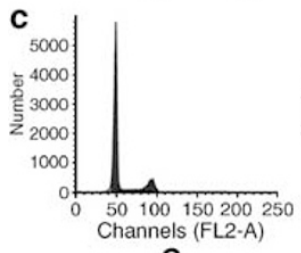

C

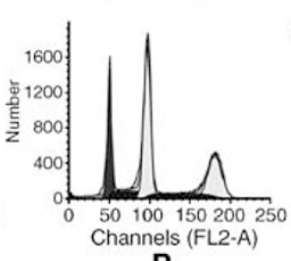

$\mathbf{R}$

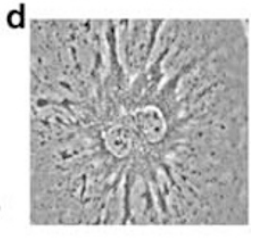

Figure 2 Effects of reversine treatment on murine fibroblast. (a) Cell count was plotted versus days of culture. Control fibroblasts (treated with DMSO) and $5 \mu \mathrm{M}$ reversine-treated fibroblasts proliferation curves are shown, as well as 4-daytreated fibroblasts, after reversine removal from growth medium on day 4 of culture. (b) RT-PCR analysis of cyclin B and HSP47 expression from total mRNA extracted from control (C) and reversine-treated (R) GFP fibroblasts, normalized to $\beta$-actin levels. (c) Effects of reversine treatment on fibroblasts cell cycle. Flow cytometry analysis performed after $72 \mathrm{~h}$ of DMSO $(\mathrm{C})$ or $5 \mu \mathrm{M}$ reversine $(\mathrm{R})$ treatment. After reversine treatment for $72 \mathrm{~h}$, the tetraploid/diploid population ratio is $80: 20$. (d) Phase-contrast microphotographs of binucleated fibroblast after reversine treatment 


\section{Coculture experiments with $\mathrm{C} 2 \mathrm{C} 12$ cells}

Initial attempts to induce myogenic differentiation of primary fibroblasts by serum starvation were unsuccessful (data not shown). Moreover, treatment of fibroblasts with a known epigenetic modulator of plasticity 5 -aza-C ${ }^{27-29}(5-30 \mu \mathrm{M})$ after 4-day reversine treatment or simultaneously with reversine did not induce myogenesis (data not shown). However, when reversine-treated fibroblasts were cocultured with murine $\mathrm{C} 2 \mathrm{C} 12$ myoblasts in differentiation medium for 8 days, they differentiated into multinucleated myotubes expressing both GFP and myosin heavy chain (MHC) (Figure 3b) with remarkably high efficiency. In fact, starting from an initial ratio of $5: 1$ between $\mathrm{C} 2 \mathrm{C} 12$ and treated fibroblasts, we observed the formation of about 35\% GFPpositive myotubes (Figure $3 b$ ). Under the same coculture conditions, but with untreated fibroblasts, we observed the formation of $0.5-2 \%$ GFP-positive myotubes (Figure 3a). Moreover, reversine-treated GFP fibroblasts started to express both $\mathrm{MHC}$ and MyoD before fusing with $\mathrm{C} 2 \mathrm{C} 12$ into myotubes (Figure $3 c-d$ ). To exclude that reversine-treated fibroblasts die after removal of reversine and release GFP which is then taken up by $\mathrm{C} 2 \mathrm{C} 12$ cells, we added an homogenate of reversine-treated GFP-murine fibroblasts to differentiating $\mathrm{C} 2 \mathrm{C} 12$. As we anticipated, at the end of the differentiation process, we did not observe any GFP-positive myotube (data not shown). Finally, we verified that the phenomenon also occurs at clonal level by subjecting both murine and human fibroblasts at cloning by limiting dilution. In all clones tested, we obtained similar results to those described above (Figure 4a).

\section{Reversine-treated fibroblasts undergo myogenic differentiation independently of cell fusion with myoblasts}

To test whether human fibroblasts would also be susceptible to the effect of reversine, we treated them with $5 \mu \mathrm{M}$ reversine and observed analogous morphology changes to the ones seen with murine fibroblasts (Figure $5 a-b$ ). Then, we cocultured reversine-treated human fibroblasts with $\mathrm{C} 2 \mathrm{C} 12$ cells. Skeletal muscle differentiation in treated human fibroblasts was revealed by double immunofluorescence with antibodies that recognize $\mathrm{MHC}$ and human lamin $\mathrm{A} / \mathrm{C}$ and by RT-PCR with human-specific oligonucleotides that amplify myogenic gene products. Figure $5 \mathrm{~d}$ shows two human nuclei (white arrows) incorporated in murine myotubes (from C2C12 cells) expressing sarcomeric myosin in the cytoplasm. Overall, we observed the incorporation of human nuclei inside myotubes with a frequency of $25 \%$. Similar results were observed at clonal level (Figure 4b). RT-PCR analysis, performed with human-specific primers, clearly showed the appearance of the human muscle determination gene MyoD in these cocultures (Figure $5 \mathrm{c}$ ). To discriminate between cell fusion and myotube-induced myogenic determination, we
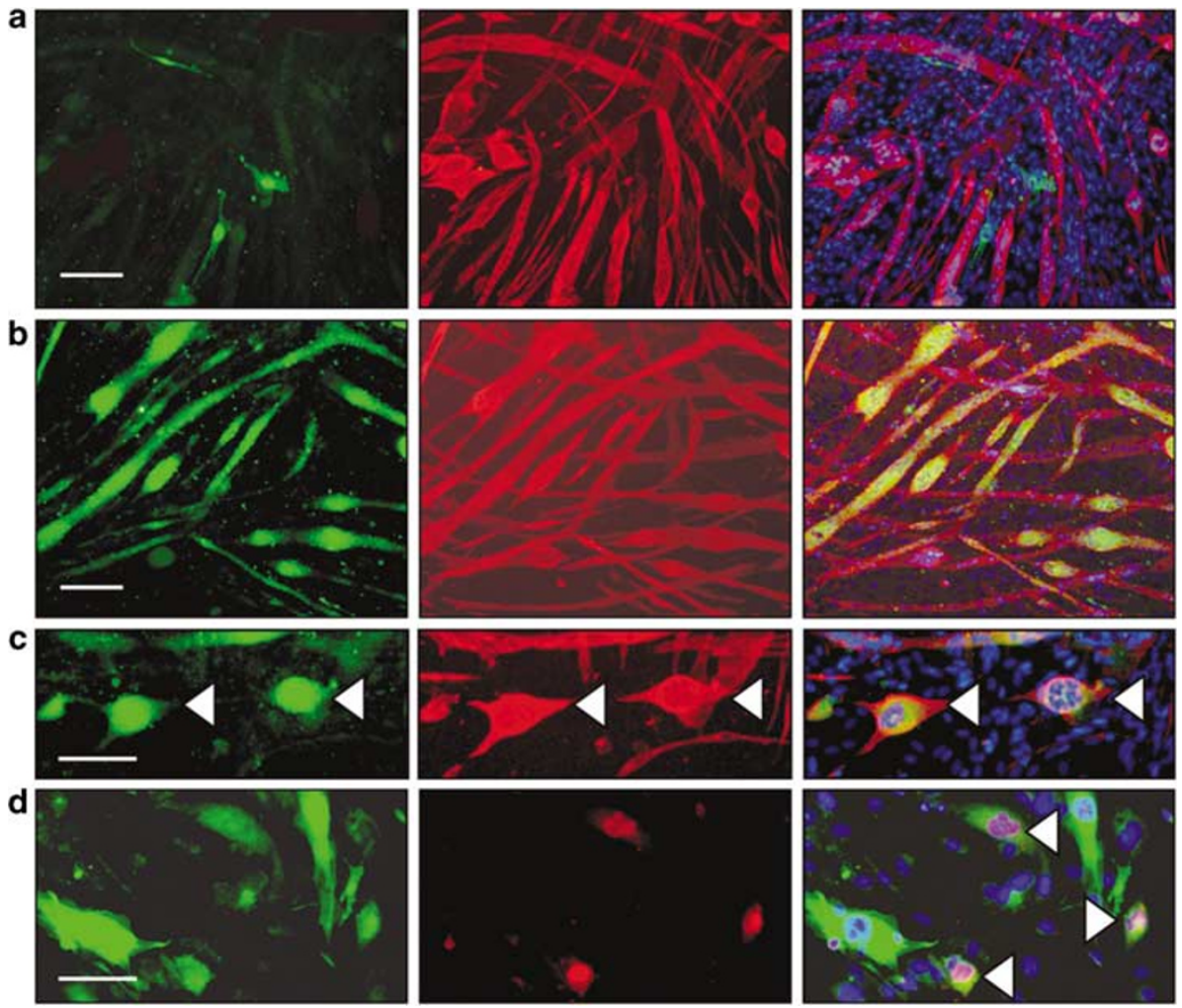

Figure 3 Cocultures of $\mathrm{C} 2 \mathrm{C} 12$ and reversine-treated GFP-positive fibroblasts. Immunofluorescence analysis of differentiated $\mathrm{C} 2 \mathrm{C} 12$ cocultured with reversine treated (b) and untreated (a) GFP-positive fibroblasts. Double staining with antibody against GFP (green) or MHC (red); nuclei were stained blue with DAPI dye. The merged images (third panels) showed the codifferentiation only in reversine-treated fibroblast cocultures. Arrows show double staining of reversine-treated murine fibroblasts with GFP (green) and MHC (red, c) or MyoD (red, d) antibodies before cells fuse into myotubes with $\mathrm{C} 2 \mathrm{C} 12$. Bar $=50 \mu \mathrm{m}$ 

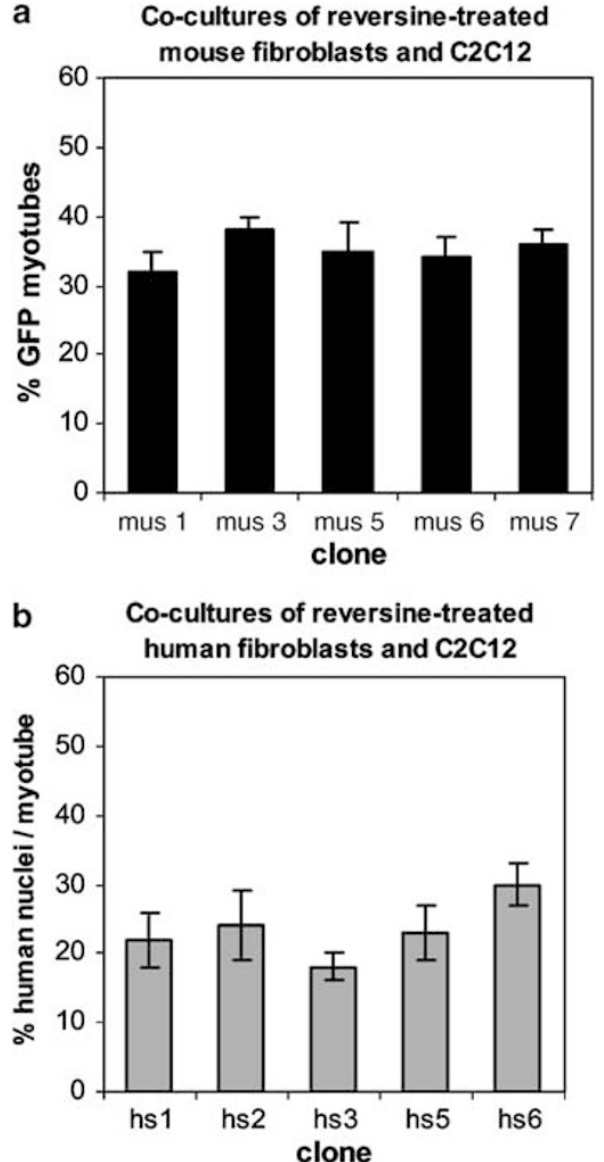

Figure 4 Cocultures of $\mathrm{C} 2 \mathrm{C} 12$ and reversine-treated clones of murine (a) or human (b) fibroblasts. The percentage of GFP-positive myotubes for murine fibroblast clones (a) or the incorporation of human nuclei (b) is reported in histograms

performed a transwell assay with reversine-treated human fibroblasts and differentiating $\mathrm{C} 2 \mathrm{C} 12$ cells. Figure 5 e shows that untreated human fibroblasts do not undergo myogenesis (Figure $5 \mathrm{e}^{\prime}$ and $\mathrm{e}^{\prime \prime}$ ) when exposed to the medium derived from differentiated $\mathrm{C} 2 \mathrm{C} 12$ myotubes (Figure $5 \mathrm{e}^{\prime \prime \prime}$ ) cultured in the upper chamber. In contrast, reversine-treated human fibroblasts underwent frequent muscle differentiation (35\% of total cells in the lower chamber) as revealed by double staining with antibodies against human lamin and MHCs (Figure $5 f^{\prime}$ and $f^{\prime \prime}$ ) when exposed to medium derived from $\mathrm{C} 2 \mathrm{C} 12$ myotubes (Figure $5 f^{\prime \prime \prime}$ ) cultured in the upper chamber. Moreover, reversine did not induce cell fusion per se, as human and mouse fibroblasts did not form hybrid cells in coculture, as revealed by mutual exclusion of human lamin and GFP (Figure 5g).

\section{Reversine-treated fibroblasts plasticity: differentiation to osteoblasts and smooth muscle cells}

To test the extent of plasticity of reversine-treated fibroblasts, we induced their differentiation to other cell types. After a 4-day reversine treatment, fibroblasts were cultured in osteogenic medium containing $0.1 \mu \mathrm{M}$ dexamethasone, $50 \mu \mathrm{g} / \mathrm{ml}$ ascorbate-2-phosphate, and $10 \mathrm{mM} \beta$-glycerophosphate. After 7 days, alkaline phosphatase (ALP) staining revealed the presence of osteoblasts (purple) in the reversinetreated fibroblasts culture (about $45 \%$ stained positive, Figure $6 \mathrm{c}$ ), whereas untreated fibroblasts were negative to ALP staining (Figure 6a). Moreover, when reversine-treated fibroblasts were cultured in Dulbecco's modified Eagle's medium (DMEM) containing $1 \%$ fetal bovine serum (FBS) and transforming growth factor-beta $1(10 \mathrm{ng} / \mathrm{ml})$ for 5 days, cells differentiated into smooth muscle cells (about $20 \%$ of treated cells, Figure $6 c$ ), as revealed by immunofluorescence with smooth muscle $\alpha$-actin ( $\alpha$-SMA) antibody (Figure $6 b$ ).

\section{In vivo muscle regeneration}

The in vivo myogenic ability of reversine-treated murine fibroblasts was tested by direct injection into cardiotoxininjured TA muscle of wild-type syngeneic mice. Four weeks after fibroblast injection, control and treated animals were killed and immunofluorescence analysis of TA muscle sections was performed. Remarkably, GFP-positive myofibers were observed in all sections of muscles injected with reversine-treated fibroblasts, at a frequency ranging from 5 to $12 \%$ at the injection side (Figure $7 \mathrm{~b}, \mathrm{c}$ and $\mathrm{e}$ ). Interestingly, GFP accumulated in the center of the fiber, similar to its localization in treated fibroblasts in vitro; the basis of this phenomenon remains to be investigated. On the contrary, no GFP-positive fibers were observed in the contralateral leg first treated with cardiotoxin and then with control fibroblasts (Figure 7a). GFP- and MHC- positive fibers are shown in Figure 7e; a higher magnification of regenerating, GFPpositive, centrally nucleated fibers are shown in Figure 7c. Reversine-treated fibroblasts did not cause any apparent adverse effect in vivo. Moreover, GFP-positive, untreated fibroblasts were exclusively located in the interstitium of muscle fibers and did not contribute to muscle fiber formation (Figure 7a).

\section{Discussion}

Ding and Schultz ${ }^{10}$ pioneered studies aimed at designing and developing a series of synthetic molecules capable of selectively controlling stem cell fate. Very recently, a synthetic 2,6-disubstituted purine, which they named reversine, was identified from a pool of several thousand molecules of a combinatorial library, and proposed to induce de-differentiation in mouse muscle cells. ${ }^{13}$ Stimulated by the new perspective generated by this discovery, we tested reversine on an accessible and easily expandable primary cell culture, such as dermal fibroblasts. This approach offers a robust source of cells that could be induced to differentiate into myotubes by coculture with $\mathrm{C} 2 \mathrm{C} 12$ myoblasts in differentiation medium. Additionally, this is the first study to evaluate reversine-mediated plasticity changes in primary cells, which confers further support to a potential therapeutic application. Despite the fact that reversine exerts effects on $\mathrm{C} 2 \mathrm{C} 12$ myoblasts, this is an immortalized line established in vitro, and 


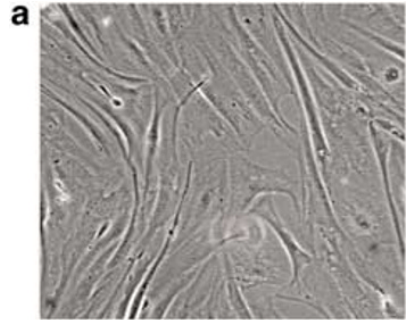

b
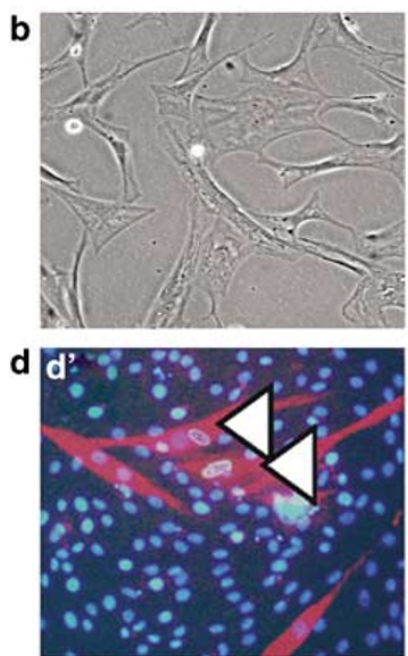

e e'

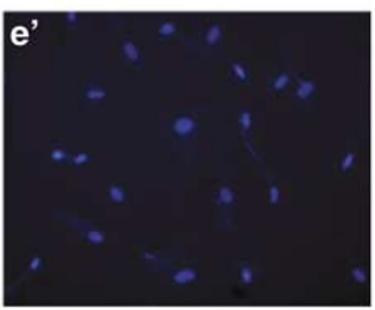

f $\mathbf{f}^{\prime}$

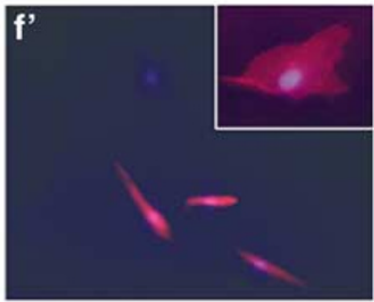

g

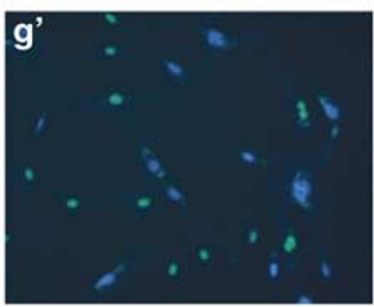

c

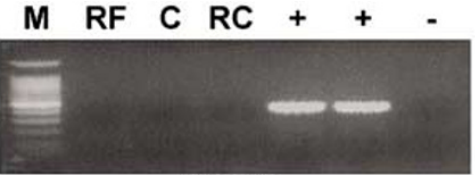

hMYF5

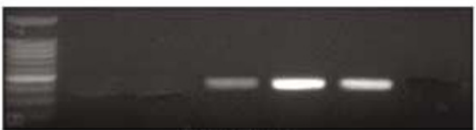

hMYOD

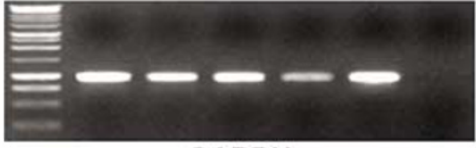

GAPDH
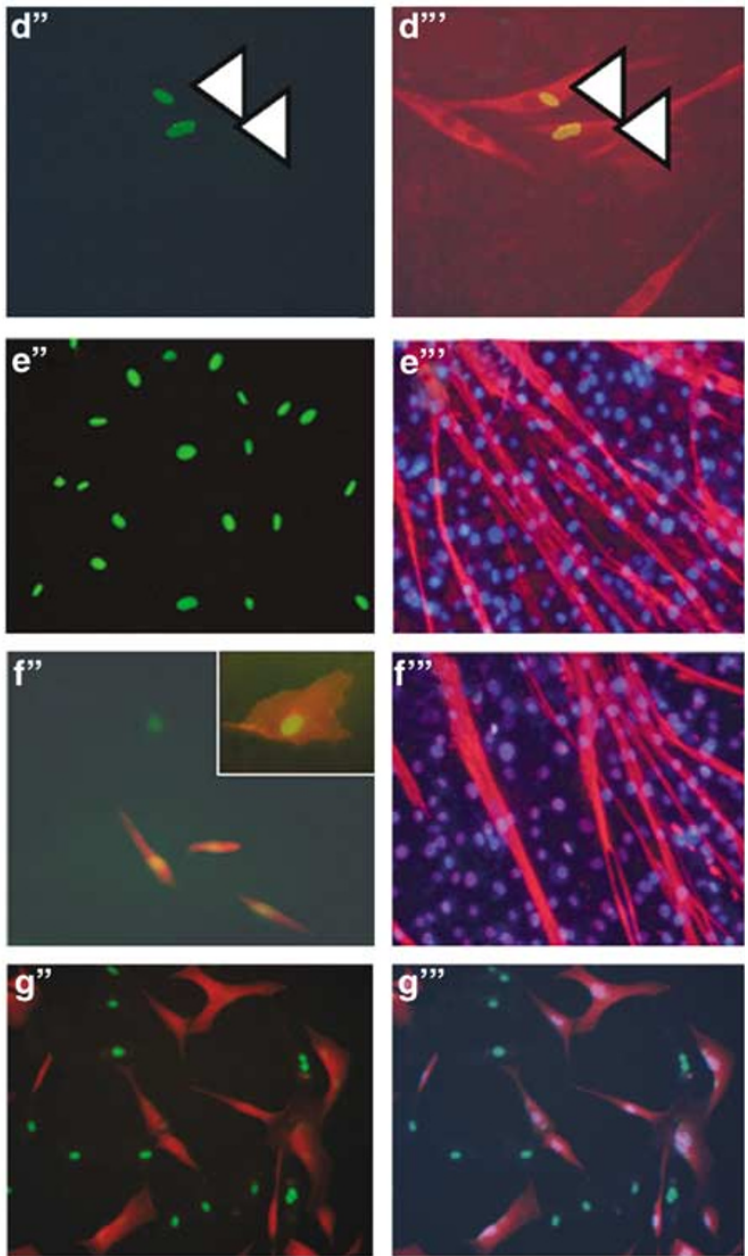

Figure $5 \mathrm{C} 2 \mathrm{C} 12$ have been cocultured with reversine-treated (b) and untreated (a) human fibroblasts; double immunofluorescence with antibody against humanspecific lamin A/C (d $\mathbf{d}^{\prime \prime}$, green) or MHC ( $\mathbf{d}^{\prime}$, red); merge is shown in $\mathbf{d}^{\prime \prime \prime}$. Nuclei were stained blue with DAPI dye; arrows show human nuclei incorporated in murine myotubes. RT-PCR analysis has been performed with human-specific oligos, Myf5, MyoD and non-species-specific GAPDH (c): M, marker; RF, reversine-treated human fibroblasts; $\mathrm{C}$, human fibroblasts-C2C12 cocultures; $\mathrm{RC}$, reversine-treated human fibroblasts-C2C12 cocultures; + , human myoblasts as positive controls; -, $-\mathrm{RT}$ of human myoblasts as negative control. (e-f) Transwell culture assay of reversine-treated (f) and untreated (e) human fibroblasts and differentiating $\mathrm{C} 2 \mathrm{C} 12$. All nuclei are stained with both DAPI (blue, $\mathbf{e}^{\prime}$ and $\mathbf{f}^{\prime}$ ) and human-specific lamin A/C (green, $\mathbf{e}^{\prime \prime}$ and $\left.\mathbf{f}^{\prime \prime}\right)$ and human MHC $\left(\right.$ red, $\left.\mathbf{f}^{\prime}, \mathbf{f}^{\prime \prime}\right)$. Enlargements $(20 \times)$ of MHC-positive reversine treated human fibroblasts are shown in inserts in $\mathbf{f}^{\prime}$ and $\mathbf{f}^{\prime \prime}$. Differentiating $\mathrm{C} 2 \mathrm{C} 12$ present in the lower wells of the transwell system are shown in $\mathbf{e}^{\prime \prime \prime}$ and $\mathrm{f}^{\prime \prime \prime}$ panels and stained with both DAPI (blue) and $\mathrm{MHC}(\mathrm{red})$. (g) Coculture of murine and human fibroblasts treated for 4 days with $5 \mu \mathrm{M}$ reversine. All nuclei are stained with both DAPI (blue) and human-specific lamin A/C, green $\left(\mathbf{g}^{\prime}\right)$. GFP-labeled murine fibroblasts $\left(\mathbf{g}^{\prime \prime}\right.$, red) do not fuse with human fibroblasts (human specific lamin A/C, green). Merge reveals no fusion between human and murine fibroblasts $\left(\mathbf{g}^{\prime \prime \prime}\right)$ 

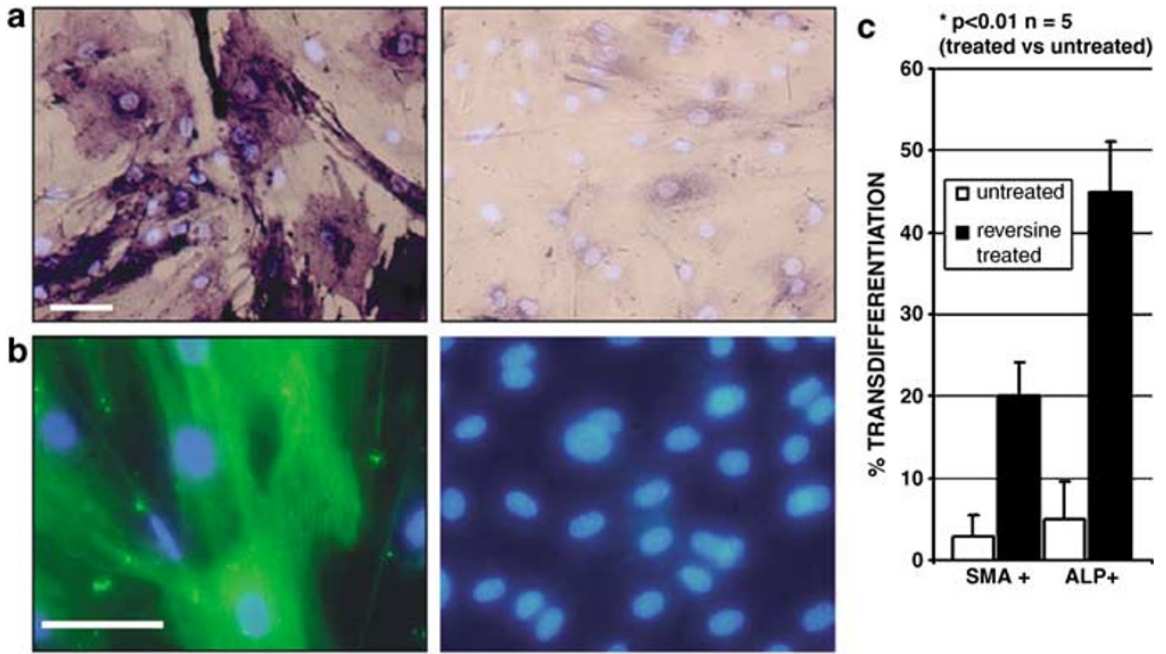

Figure 6 Differentiation of reversine-treated (left panels) and untreated (right panels) fibroblasts to osteoblasts and smooth muscle cells. (a) ALP staining (purple) of day 7 osteogenic differentiation culture; $b a r=100 \mu \mathrm{m}(\mathbf{b})$ immunofluorescence analysis of 5 days culture to induce smooth alpha actin (green). Nuclei are stained with DAPI (blue). The percentage of differentiation are reported in the histograms in (c)

therefore its response may not be faithfully predictive of the in vitro and in vivo response of a primary cell. ${ }^{30}$

Reversine treatment of primary cultures of dermal fibroblasts caused a dramatic change in both cell morphology and proliferation. Cells not only enlarged in their size up to nine times compared to control cells (Figure 1a-b), but they also increased their adhesion to the culture plate, as noted during trypsin detachment. The fibroblast marker HSP47 progressively disappeared after treatment, supporting a possible reversine-induced change in lineage commitment (Figure 2b). However, expression of specific stem cell markers was not observed in treated cells. Moreover, reversine treatment reduced cell proliferation and led to the formation of a tetraploid cell population (Figure $2 c-d$ ), which reverted to normal ploidy upon drug withdrawal (Figure 2a). Along this line, Schultz's group already reported that some 2,6,9trisubstituited purines, analogs to reversine, are strong cyclin-dependent kinase inhibitors and lead to the formation of cells with two distinct nucleated microtubule arrays. ${ }^{20}$ The biological significance of this effect on the cell cycle, observed even at the lowest active concentrations of reversine, is still unclear. Nevertheless, polyploidy is a normal developmental process that occurs in several cellular systems including plants, insects, and mammals, as in skeletal muscle fibers and megakaryocytes, and is often beneficial to the cell, as it allows an increase in metabolic output, cell mass, and cell size, without the need to devote energy to carry on all aspects of cellular division. ${ }^{31}$ As a result of the treatment, we observed that reversine-treated fibroblasts remain in a quiescent state until properly triggered. In fact, we could induce myogenic differentiation of treated fibroblasts by coculture with $\mathrm{C} 2 \mathrm{C} 12$ in a differentiation medium. Strikingly, reversine-treated fibroblasts differentiated very efficiently into myotubes after 7-8 days of coculture (Figure $3 b$ ). This remarkable and unexpected fate change was at least one order of magnitude greater than that observed in all previous reported data even in comparison with different types of 'bona fide' stem cells. $^{32-34}$ Moreover, during coculturing, reversine-treated fibroblasts expressed striated muscle-specific genes such as those encoding $\mathrm{MHC}$ and $\mathrm{MyoD}$, before fusion into multinucleated myotubes (Figure $3 c-d$ ). Thus myogenesis can be influenced in primary mononucleated fibroblasts by signals emanating from neighboring cells. As a consequence of the acquired myogenic phenotype, fusion with $\mathrm{C} 2 \mathrm{C} 12$ cells occurs. Moreover, transwell culture assays of reversinetreated human fibroblasts and differentiating $\mathrm{C} 2 \mathrm{C} 12$ caused myogenic differentiation of fibroblasts (Figure 5f). This result was unexpected as previous attempts to induce differentiation of mouse fibroblasts with medium conditioned by myotubes had proven to be ineffective. This may be due to the short halflife of the active molecules; furthermore, the transwell experiment induced myogenic differentiation in both mouse and human fibroblasts, although the latter were far more responsive than mouse cells. Although the basis of this difference is still unclear, it is promising for future clinical exploitation.

When we cocultured human and murine fibroblasts in the presence of reversine, we did not observe any cell fusion (Figure $5 \mathrm{~g}$ ), further supporting the notion that reversine is not a fusogenic molecule. Importantly, the stimulation of myogenic differentiation of fibroblasts also occurred in vivo, in a cardiotoxin model of skeletal muscle regeneration, indicating that the effect on cellular plasticity is not limited to the tissue culture environment (Figure 7). In fact, 4 weeks after injection of reversine-treated fibroblasts in injured TA muscle, GFPand $\mathrm{MHC}$-positive fibers were observed in all sections analyzed (Figure 7b, c, and e). On the other hand, no GFPpositive fibers were observed in the contralateral leg treated with normal fibroblasts (Figure 7a), which demonstrates that only reversine-treated fibroblasts acquire the capability of regenerating muscle fibers. Our in vivo experiments showed no noticeable toxicity of reversine-treated fibroblasts (up to $5 \mu \mathrm{M})$, although we cannot exclude toxicity at higher concentrations. Furthermore, we observed similar results with 

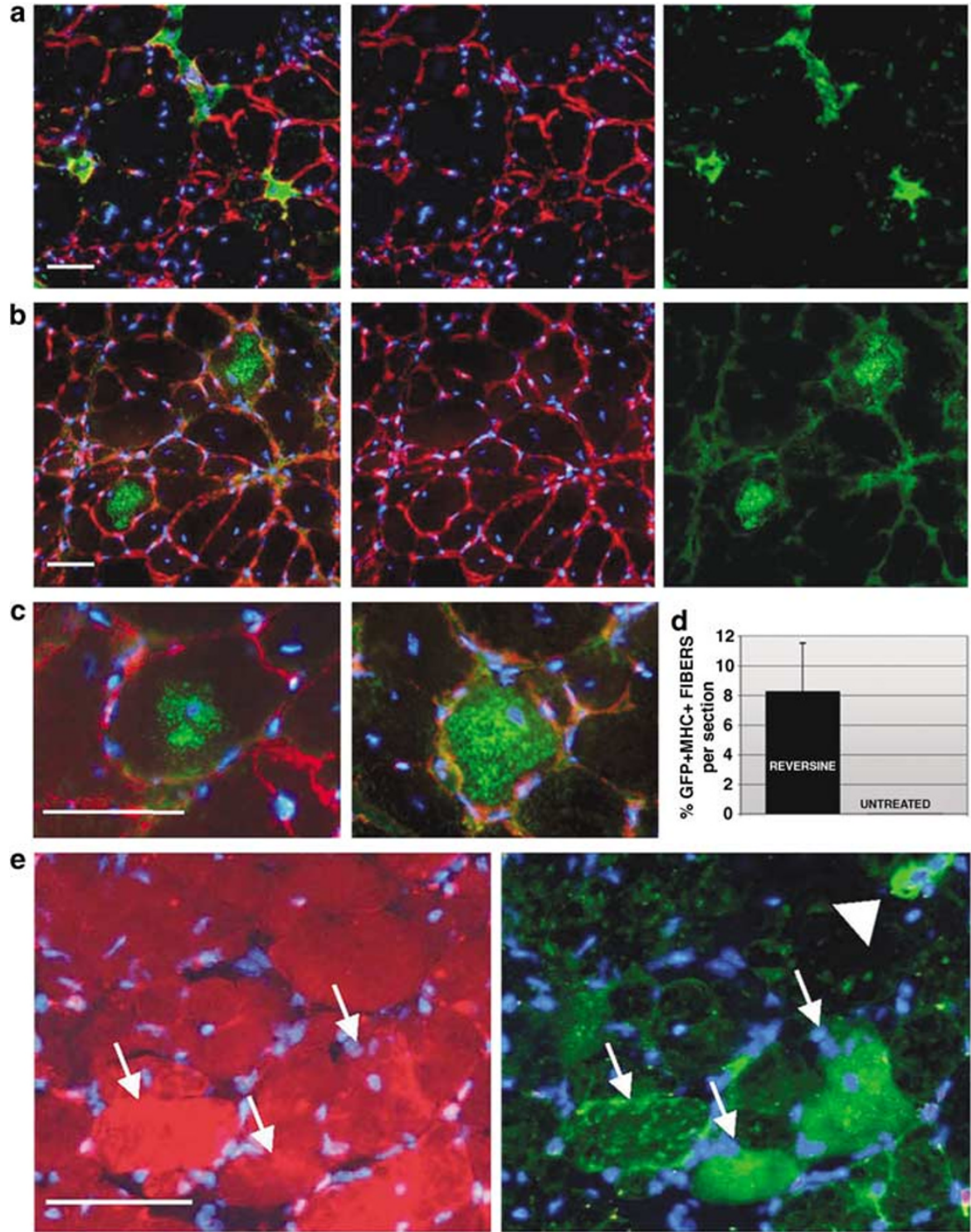

Figure 7 Intramuscular injection of reversine-treated fibroblasts in a crushed-induced regeneration model. Immunofluorescence analysis of TA of C57 mice transplanted with reversine-treated (b, c, and e) and untreated (a) GFP-positive fibroblasts. Staining with antibodies against laminin (red) in (a, b, and c), or GFP (green) in (a, b, $\mathbf{c}$, and $\mathbf{e})$, or MHC (red) in (e); sections were also stained with DAPI (blue). In (b), the GFP signal is clearly detected inside the fibers and delimited by the laminin membrane signal. (c) High magnification of central nucleated fibers expressing GFP. In (d), percentage of GFP-positive and MHC-positive fibers per section analyzed. In (e), arrows show three MHC-positive fibers expressing GFP and the arrowhead shows undifferentiated cells; bar $=100 \mu \mathrm{m}$

reversine-treated human dermal fibroblasts, showing that reversine effects are not restricted to rodent cells and may indeed have a potential clinical application.

In conclusion, our data show that primary murine and human fibroblasts treated with reversine can be induced to differentiate into skeletal muscle at high frequency both in vitro and in vivo. It had been previously shown that fibroblasts from different sources have the ability to differentiate into skeletal muscle, but with a very low frequency, below that of possible therapeutic efficacy. Indeed, even SP cells and mesenchymal stem cells differentiate into skeletal muscle at frequency that are below $1 \%$. Moreover, although some recent negative results have been recently reported using reversine-treated $\mathrm{C} 2 \mathrm{C} 12,{ }^{35}$ we confirmed and extended previous findings, ${ }^{13}$ showing that a substantial fraction of treated fibroblasts could be converted into osteoblasts and smooth muscle cells under appropriate conditions. The mechanism by which reversine exerts its effects on fibroblasts is still unknown. Reversine itself does not activate MyoD or Myf5 in fibroblasts and in fact spontaneous myogenic differentiation of treated cells does not occur. Therefore, we can only speculate that reversine reprograms somatic cells to a state of increased plasticity so that further stimuli, such as cell-cell interactions may activate differentiation at high frequency. Further work is necessary to elucidate the mechanism of action of this molecule and to further exploit its potential for cell therapy approaches. In addition, genes subject to reversine treatment in fibroblasts may be identified and become an important tool to activate 
myogenic competence in these cells, independently of exposure to the molecule itself. The reversible changes on fibroblast-specific transcripts and morphology are similar to those reported following treatment with epigenetic modulators of plasticity, such as 5-aza-C and trichostatin-A. ${ }^{27-29}$ Epigenetic mechanisms exert a prominent role during differentiation and cell fate decisions. ${ }^{36}$ However, we observed that exposure to 5-aza-C along with reversine failed to enhance reversine-related plasticity changes. Therefore, whether reversine effects involve epigenetic changes, as demonstrated in other critical cellular reprogramming events, ${ }^{37}$ is a topic deserving a deeper and more accurate investigation.

\section{Materials and Methods}

\section{Cell culture}

Primary mouse dermal fibroblasts expressing GFP were obtained from transgenic mice. Primary human dermal fibroblasts were prepared from a pool of healthy donors. Murine fibroblasts, human fibroblasts, and the mouse myogenic cell line $\mathrm{C} 2 \mathrm{C} 12$ in growth were maintained in DMEM high glucose supplemented with $4 \mathrm{mM}$ glutamine, $100 \mathrm{IU} / \mathrm{ml}$ penicillin, $100 \mu \mathrm{g} /$ $\mathrm{ml}$ streptomycin, and $10 \%$ (v/v) FBS. C2C12 were induced to differentiate into myotubes by replacing $10 \%$ FBS with $2 \%$ horse serum (HS) in the culture medium. Differentiation was completed in 7-8 days. All cultures were performed at $37^{\circ} \mathrm{C}$ in a humidified incubator with $5 \% \mathrm{CO}_{2}$ and $95 \%$ air.

\section{Treatment of fibroblasts with reversine}

Reversine was prepared according to the published procedure ${ }^{13}$ and purity $(\geqslant 98 \%)$ was checked by HPLC and LC-MS analysis. Mouse or human fibroblasts $\left(8 \times 10^{4}\right)$ were plated in $60 \mathrm{~mm}$ dishes in DMEM supplemented with $10 \%$ FBS. Fibroblasts were treated with reversine, dissolved in DMSO, at concentrations $0.1-10 \mu \mathrm{M}$ in 10\% FBS DMEM, 18 $24 \mathrm{~h}$ after seeding. Control cells were incubated with $0.05 \%$ DMSO Treatment was carried out for 4 days without growth medium changes. In some experiments, fibroblasts were treated with reversine or DMSO for 4 days and then shifted to DMEM containing 10-20\% (v/v) FBS and grown for 25 days. Cell morphology and proliferation were evaluated with phasecontrast microscope and cells were counted on a hemocytometer.

\section{Cell morphology and growth curve}

Mouse fibroblasts $\left(8 \times 10^{4}\right)$ were plated in $60 \mathrm{~mm}$ dishes and treated with reversine or DMSO. Cell morphology was examined daily with a phasecontrast microscope (IX50 Olympus) connected with an image analyzer. At each passage, cells were counted on a hemocytometer. Cell viability was determined by trypan blue dye exclusion assay.

\section{Cytotoxicity assay}

Four days after incubation with reversine or DMSO, cytotoxicity was measured using in vitro toxicology assay kit, XTT based, ${ }^{18}$ (Sigma) according to the manufacturer's protocol. Incubation medium was collected after $3 \mathrm{~h}$ and read spectrophotometrically at a wavelength of $450 \mathrm{~nm}$.

\section{Flow cytofluorimetry}

Control and treated cells were harvested and fixed in $70 \%$ ethanol and kept at $4^{\circ} \mathrm{C}$ before staining. Fixed cells were resuspended in $1 \mathrm{ml}$ of a solution containing $5 \mu \mathrm{g} / \mathrm{ml}$ propidium iodide (Sigma) in phosphatebuffered saline (PBS) (Gibco Brl), $25 \mu \mathrm{l}$ RNAse (Sigma) $1 \mathrm{mg} / \mathrm{ml}, 25 \mu \mathrm{l}$ of Nonidet P40 (Sigma) $0.15 \%$ in water, and stained overnight at $4^{\circ} \mathrm{C}$ in the dark. Cell analysis was performed on at least 20.000 events for each sample by FACSCalibur System (BD) and DNA profile was analyzed by MODFit 3.0 (Verity Software House).

\section{Gene expression}

Total RNA from control or treated fibroblast were extracted (Trizol, ${ }^{38}$ Invitrogen) and analyzed by RT-PCR, using $\beta$-actin as internal standard (see Table 1 for primer sequences).

\section{Fibroblast coculture with $\mathrm{C} 2 \mathrm{C} 12$ and myogenic conversion}

Murine or human fibroblasts $\left(4 \times 10^{4}\right.$ cells/60 mm dish) were cultured in the presence of $5 \mu \mathrm{M}$ reversine or DMSO for 4 days, then cells were washed twice with PBS and twice with DMEM containing 10\% FBS. C2C12 myoblasts $\left(2 \times 10^{5}\right.$ cells $/ 60 \mathrm{~mm}$ dish) were then added to fibroblasts-containing plates. The following day cocultures were shifted in DMEM supplemented with $2 \%$ HS. Differentiation was carried out for 8

Table 1 Primers used for gene expression

\begin{tabular}{|c|c|c|}
\hline Gene & Left primer & Right primer \\
\hline $\begin{array}{l}\beta \text {-actin } \\
\text { HSP47 } \\
\text { Cyclin A } \\
\text { Cyclin B } \\
\text { Cyclin D1 } \\
\text { Cyclin E1 } \\
\text { p16 } \\
\text { p21 } \\
\text { p27 } \\
\text { CD34 } \\
\text { CD45 } \\
\text { CD73 } \\
\text { CD105 } \\
\text { Pax3 } \\
\text { Pax7 }\end{array}$ & $\begin{array}{l}\text { 5'-GCTCGTCGTCGACAACGGCTC-3' } \\
\text { 5'-CCTGAGGTCACCAAGGATGT-3' } \\
\text { 5'-GATCTGACCGTTCCAACCAC-3' } \\
\text { 5'-GTTGTGTGCCCAAGAAGATG-3' } \\
\text { 5'-TTGACTGCCGAGAAGTTGTG-3'3 } \\
\text { 5'-TGGCTGCTTCAGATTTCCTT-3' } \\
\text { 5'-ACTGCGAGGACCCCACTAC-3' } \\
\text { 5'-GACCTGGGAGGGGACAAG-3'3 } \\
\text { 5'-ATTGGGTCTCAGGCAAACTC-3' } \\
\text { 5'-GGGTAGCTCTCTGCCTGATG-3' } \\
\text { 5'-CTGAAGACCCTCACCTGCTC-3' } \\
\text { 5'-TCCCCCATTGATGAGAAGAA-3' } \\
\text { 5'-CTTCCAAGGACAGCCAAGAG-3' } \\
\text { 5'-GGAAGCAGAAGAAAGCGAGA-3' } \\
\text { 5'-GGTCCCCAGGATGATGAGA-3' }\end{array}$ & $\begin{array}{l}\text { 5'-CAAACATGATCTGGGTCATCTTCTC-3' } \\
\text { 5'-CTGCAGCTTCTCCTTCTCGT-3' } \\
\text { 5'-CAGCAACCAAGGAAGGAAGA-3' } \\
\text { 5'-CTACGGAGGAAGTGCAGAGG-3' } \\
\text { 5'-CTGGCATTTTGGAGAGGAAG-3'3 } \\
\text { 5'-GTGTGGGTCTGGATGTTGTG-3' } \\
\text { 5'-CAGCGGTACACAAAGACCAC-3' } \\
\text { 5'-TGCGCTTGGAGTGATAGAAA-3' } \\
\text { 5'-TCTGTTCTGTTGGCCCTTTT-3' } \\
\text { 5'-TCTCTGAGATGGCTGGTGTG-3'3 } \\
\text { 5'-CACTTGCACCATCAGACACC-3' } \\
\text { 5'-TCGACACTTGGTGCAGAGAA-3' } \\
\text { 5'-AGGACCATGCAGGATGAGAA-3' } \\
\text { 5'-GCTCCTCCCTGGTGTAAATG-3' } \\
\text { 5'-TTGATGAAGACCCCACCAAG-3' }\end{array}$ \\
\hline
\end{tabular}


days. Cells were then fixed with $4 \%$ (w/v) paraformaldehyde at room temperature (RT) for $10 \mathrm{~min}$ and then permeabilized with $0.1 \%(\mathrm{w} / \mathrm{v})$ Triton $\mathrm{X}-100$ in PBS for $5 \mathrm{~min}$. Cells were incubated overnight at $4^{\circ} \mathrm{C}$ with the following primary antibodies: anti-GFP polyclonal antibody (Molecular Probes) at 1:200 dilution, anti-MHC (MF20) monoclonal antibody at 1:5 dilution, anti-human specific lamin $\mathrm{A} / \mathrm{C}$ monoclonal antibody (GeneTex) at $1: 100$ dilution. After incubation, cells were washed three times in PBS and incubated with the appropriate FITC- or TRIC-conjugated secondary antibodies $1 \mathrm{~h}$ at RT. After washing in PBS, cells were analyzed under a fluorescent microscope (Nikon Eclipse TE 200 microscope equipped with a $d \times m 1200$ Nikon camera). For the coculture experiments of murine fibroblasts with $\mathrm{C} 2 \mathrm{C} 12$ cells, the percentages reported of GFP myotubes were calculated by counting the number of GFP-positive myotubes compared to the total myotubes per field. In the case of cocultures with human fibroblasts, we counted the ratio of human nuclei inside or outside the myotubes. The numbers reported are the average of 10 random fields for each experiment. Cell nuclei were counterstained with $4^{\prime}, 6$-diamidino2-phenyindole (DAPI, Sigma). Cocultures of human fibroblasts with C2C12 were also analyzed by RT-PCR with human-specific oligos for Myf5 and MyoD using non-species specific GAPDH as internal standard.

\section{Transwell culture assay with reversine-treated fibroblasts and $\mathrm{C} 2 \mathrm{C} 12$ cells}

The fibroblast/C2C12 cell transwell culture studies were conducted similarly to the coculture experiments except that fibroblasts treated with reversine (4 days), or untreated, were placed on the bottom of the six-well plate in a thin layer of media and left in the incubator overnight; then a transwell cell culture insert ( $3.0 \mu \mathrm{m}$ pore size, Costar, Cambridge, MA, USA) containing differentiating $\mathrm{C} 2 \mathrm{C} 12$ was added to the well, and maintained for 5 days, changing the common culture medium every $48 \mathrm{~h}$. After 5 days, the cells were washed with PBS, fixed with 2\% PFA and processed for immunofluorescence analysis. Immunostaining was carried out after membrane permeabilization with anti-MHC polyclonal antibody (Sigma) and anti-human nuclei monoclonal antibody (Chemicon, USA). After incubation, cells were washed three times in PBS and incubated with the appropriate FITC- or TRIC-conjugated secondary antibodies $1 \mathrm{~h}$ at RT. Cell nuclei were counterstained with DAPI (Sigma). After washing in PBS, cells were analyzed under a fluorescent microscope (Nikon Eclipse TE 200 microscope equipped with a $\mathrm{d} \times \mathrm{m} 1200$ Nikon camera).

\section{Transdifferentiation to osteoblasts and smooth muscle cells}

To induce osteogenic transdifferentiation, reversine or DMSO-treated fibroblasts were cultured in 10\% FBS-DMEM supplemented with $0.1 \mu \mathrm{M}$ dexamethasone, $50 \mu \mathrm{g} / \mathrm{ml}$ ascorbate-2-phosphate, $10 \mathrm{mM} \beta$-glycerophosphate. Treatment was carried out for 7 days. Cells were fixed with $2 \%$ paraformaldehyde at RT for $10 \mathrm{~min}$ and then osteogenic differentiation was assessed with ALP staining (Sigma). Moreover, after reversine or DMSO treatment for 4 days, fibroblasts were transdifferentiated to smooth muscle cells with transforming growth factor-beta 1 (Sigma, $10 \mathrm{ng} / \mathrm{ml}$ in DMEM containing $1 \%$ FBS for 5 days). Then cells were fixed with $2 \%$ paraformaldehyde in PBS for 10 min. Immunostaining was carried out with anti- $\alpha$-SMA monoclonal antibody (Sigma) at 1:100 diluition. After incubation with primary antibody, cells were washed three times in PBS and incubated with FITC-conjugated secondary antibodies $1 \mathrm{~h}$ at RT. After washing in PBS, cells were analyzed under a fluorescent microscope
(Nikon Eclipse TE 200 microscope equipped with a $\mathrm{d} \times \mathrm{m} 1200$ Nikon camera). Cell nuclei were counterstained with DAPI (Sigma).

\section{Transplantation of reversine-treated fibroblasts into regenerating skeletal muscle}

C57 mice were bred and maintained in the San Raffaele Hospital SPF animal care facility and all experiments were carried out in accordance with European law for animal laboratory experiments. Host muscles were injected with cardiotoxin $(50 \mathrm{ng} / \mathrm{ml}$ in $10 \mu \mathrm{l}) 24 \mathrm{~h}$ before fibroblast transplantation in the TA muscles. ${ }^{39}$ A Hamilton syringe was used to inject the donor cells $\left(10^{6}\right.$ in $20 \mu$ l PBS total volume for each muscle) into the host TA muscle after the skin incision. At 35 days after cell transplantation, the mice were killed and the muscle processed for immunofluorescence according to the following protocol. Muscle samples from mice after transplantation with reversine-treated and untreated fibroblasts were frozen in liquid nitrogen, cooled isopentane and serial $10 \mu \mathrm{m}$ thick sections were cut with a Leyca cryostat. Tissue sections were stained with hematoxylin eosin $(\mathrm{H} \& \mathrm{E})$ or processed for immunofluorescence analysis. Briefly, samples were permeabilized with $0.1 \%$ Triton X$100,0.2 \%$ bovine serum albumin (BSA) in PBS for $10 \mathrm{~min}$ at RT. Tissue sections were washed three times with $0.2 \%$ BSA in PBS, and incubated overnight at $4{ }^{\circ} \mathrm{C}$ with the following primary antibodies: anti-GFP polyclonal antibody (1:200), anti-MHC (MF20) monoclonal antibody (1:5), and antilaminin polyclonal antibody (Sigma) $(1: 100)$. The number of GFP-positive fibers was calculated in three different experiments, counting the positive fibers per picture field using a microscope equipped with a 10-fold magnification objective.

\section{Acknowledgements}

The authors would like to thank students Francesca Colazzo and Alessandra Colombini for their valuable help in some experiments. This study was supported by PRIN (2004), AFM, MDA, Telethon, Duchenne Parent Project, European Community, Cariplo Foundation, and Italian Ministries of Health and Research.

\section{References}

1. Alison MR, Poulsom R, Forbes S and Wright NA (2002) An introduction to stem cells. J. Pathol. 197: 419-423.

2. Blau HM, Brazelton TR and Weimann JM (2001) The evolving concept of a stem cell: entity or function? Cell 105: 829-841.

3. Wagers AJ and Weissman IL (2004) Plasticity of adult stem cells. Cell 116: 639-648.

4. Fang TC and Poulsom R (2003) Cell-based therapies for birth defects: a role for adult stem cell plasticity? Birth Defects Res Part C Embryo Today 69: 238-249

5. Huard J, Cao B and Qu-Petersen Z (2003) Muscle-derived stem cells: potential for muscle regeneration. Birth Defects Res Part C Embryo Today 69: 230-237.

6. Reyes M, Dudek A, Jahagirdar B, Koodie L, Marker PH and Verfaille CM (2002) Origin of endothelial progenitors in human postnatal bone marrow. J. Clin. Invest. 109: 337-346.

7. Minasi MG, Riminucci M, De Angelis L, Borello U, Berarducci B, Innocenzi A, Caprioli A, Sirabella D, Baiocchi M, De Maria R, Boratto R, Jaffredo T, Broccol V, Bianco P and Cossu G (2002) The meso-angioblast: a multipotent, selfrenewing cell that originates from the dorsal aorta and differentiates into most mesodermal tissues. Development 129: 2773-2783.

8. Bachrach E, Li S, Perez AL, Schienda J, Liadaki K, Volinski J, Flint A, Chamberlain $J$ and Kunkel LM (2004) Systemic delivery of human microdystrophin to regenerating mouse dystrophic muscle by muscle progenitor cells. Proc. Natl. Acad. Sci. USA 101: 3581-3586. 
9. Raff M (2003) Adult stem cell plasticity: fact or artifact? Annu. Rev. Cell. Dev. Biol. 19: 1-22.

10. Ding S and Schultz PG (2004) A role for chemistry in stem cell biology. Nat. Biotechnol. 22: 833-840.

11. Rosania GR, Chang YT, Perez O, Sutherlin D, Dong H, Lockhart DJ and Schultz PG (2000) Myoseverin, a microtubule-binding molecule with novel cellular effects. Nat. Biotechnol. 18: 304-308.

12. Perez OD, Chang YT, Rosania G, Sutherlin D and Schultz PG (2002) Inhibition and reversal of myogenic differentiation by purine-based microtubule assembly inhibitors. Chem. Biol. 9: 475-483.

13. Chen S, Zhang Q, Wu X, Schultz PG and Ding S (2004) Dedifferentiation of lineage-committed cells by a small molecule. J. Am. Chem. Soc. 126: $410-411$.

14. Katagiri T, Yamaguchi A, Komaki M, Abe E, Takahashi N, Ikeda T, Rosen V, Wozney JM, Fujisawa-Sehara A and Suda T (1994) Bone morphogenetic protein-2 converts the differentiation pathway of $\mathrm{C} 2 \mathrm{C} 12$ myoblasts into the osteoblast lineage. J. Cell. Biol. 127: 1755-1766.

15. Holst D, Luquet S, Kristiansen K and Grimaldi PA (2003) Roles of peroxisome proliferator-activated receptors delta and gamma in myoblast transdifferentiation. Exp. Cell. Res. 288: 168-176.

16. Fux C, Mitta B, Kramer BP and Fussenegger M (2004) Dual-regulated expression of C/EBP-alpha and BMP-2 enables differential differentiation of $\mathrm{C} 2 \mathrm{C} 12$ cells into adipocytes and osteoblasts. Nucleic. Acids Res. 32: e1

17. Kumar TK, Jayaraman G, Lee CS, Arunkumar Al, Sivaraman T, Samuel D and Yu C (1997) Snake venom cardiotoxins-structure, dynamics, function and folding. J. Biomol. Struct. Dyn. 15: 431-463.

18. Roehm NW, Rodgers GH, Hatfield SM and Glasebrook AL (1991) An improved colorimetric assay for cell proliferation and viability utilizing the tetrazolium salt XTT. J. Immunol. Methods 142: 257-265.

19. Gray NS, Wodicka L, Thunnissen AM, Norman TC, Kwon S, Espinoza FH, Morgan DO, Barnes G, LeClerc S, Meijer L, Kim SH, Lockhart DJ and Schultz PG (1998) Exploiting chemical libraries, structure, and genomics in the search for kinase inhibitors. Science 281: 533-538.

20. Chang YT, Gray NS, Rosania GR, Sutherlin DP, Kwon S, Norman TC, Sarohia R, Leost M, Meijer L and Schultz PG (1999) Synthesis and application of functionally diverse 2, 6, 9-trisubstituted purine libraries as CDK inhibitors. Chem. Biol. 6: 361-375.

21. Guidotti JE, Bregerie O, Robert A, Debey P, Brechot C and Desdouets C (2003) Liver cell polyploidization: a pivotal role for binuclear hepatocytes. J. Biol. Chem. 278: 19095-19101.

22. Kuroda K and Tajima S (2004) HSP47 is a useful marker for skin fibroblasts in formalin-fixed, paraffin-embedded tissue specimens. J. Cutan. Pathol. 31 241-246.

23. Civin Cl, Strauss LC, Brovall C, Fackler MJ, Schwartz JF and Shaper JH (1984)

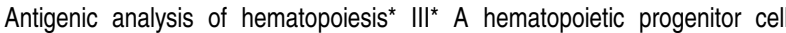
surface antigen defined by a monoclonal antibody raised against KG-1a cells J. Immunol. 133: 157-165.

24. Lee JY, Qu-Petersen Z, Cao B, Kimura S, Jankowski R, Cummins J, Usas A Gates C, Robbins P, Wernig A and Huard J (2000) Clonal isolation of muscle- derived cells capable of enhancing muscle regeneration and bone healing. J. Cell. Biol. 150: 1085-1100.

25. Seale $P$, Sabourin LA, Girgis-Gabardo A, Mansouri A, Gruss $P$ and Rudnicki MA (2000) Pax7 is required for the specification of myogenic satellite cells. Cell 102: $777-786$

26. Pittenger MF, Mackay AM, Beck SC, Jaiswal RK, Douglas R, Mosca JD, Moorman MA, Simonetti DW, Craig S and Marshak DR (1999) Multilineage potential of adult human mesenchymal stem cells. Science 284: 143-147.

27. Skliris GP, Munot K, Bell SM, Carder PJ, Lane S, Horgan K, Lansdown MR, Parkes AT, Hanby AM, Markham AF and Speirs V (2003) Reduced expression of oestrogen receptor beta in invasive breast cancer and its re-expression using DNA methyl transferase inhibitors in a cell line model. J. Pathol. 201: 213-220.

28. Milhem M, Mahmud N, Lavelle D, Araki H, DeSimone J, Saunthararajah $Y$ and Hoffman R (2004) Modification of hematopoietic stem cell fate by 5aza 2'deoxycytidine and trichostatin A. Blood 103: 4102-4110.

29. Kumakura S, Tsutsui TW, Yagisawa J, Barrett JC and Tsutsui T (2005) Reversible conversion of immortal human cells from telomerase-positive to telomerase-negative cells. Cancer Res. 65: 2778-2786.

30. Dodge JE, Okano M, Dick F, Tsujimoto N, Chen T, Wang S, Ueda Y, Dyson N and Li E (2005) Inactivation of Dnmt3b in mouse embryonic fibroblasts results in DNA hypomethylation, chromosomal instability, and spontaneous immortalization. J. Biol. Chem. 280: 17986-17991.

31. Ravid K, Lu J, Zimmet JM and Jones MR (2002) Roads to polyploidy: the megakaryocyte example. J. Cell. Physiol. 190: 7-20.

32. Lattanzi L, Salvatori G, Coletta M, Sonnino C, Cusella De Angelis MG, Gioglio L, Murry CE, Kelly R, Ferrari G, Molinaro M, Crescenzi M, Mavilio F and Cossu $G$ (1998) High efficiency myogenic conversion of human fibroblasts by adenoviral vector-mediated MyoD gene transfer. An alternative strategy for ex vivo gene therapy of primary myopathies. J. Clin. Invest. 101: 2119-2128.

33. Odelberg SJ, Kollhoff A and Keating MT (2000) Dedifferentiation of mammalian myotubes induced by msx1. Cell 103: 1099-1109.

34. McGann CJ, Odelberg SJ and Keating MT (2001) Mammalian myotube dedifferentiation induced by newt regeneration extract. Proc. Natl. Acad. Sci. USA 98: 13699-13704.

35. Perreira M, Jiang JK, Klutz AM, Gao ZG, Shainberg A, Lu C, Thomas CJ and Jacobson KA (2005) Reversine and its 2-substituted adenine derivatives as potent and selective A3 adenosine receptor antagonists. J. Med. Chem. 48: 4910-4918.

36. Lee JH, Hart SR and Skalnik DG (2004) Histone deacetylase activity is required for embryonic stem cell differentiation. Genesis 38: 32-38.

37. Blelloch RH, Hochedlinger K, Yamada Y, Brennan C, Kim M, Mintz B, Chin L and Jaenisch $R$ (2004) Nuclear cloning of embryonal carcinoma cells. Proc. Natl. Acad. Sci. USA 101: 13985-13990.

38. Chomczynski P and Sacchi N (1987) Single-step method of RNA isolation by acid guanidinium thiocyanate-phenol-chloroform extraction. Anal. Biochem. 162: $156-159$

39. Ferrari G, Cusella-De Angelis G, Coletta M, Paolucci E, Stornaiuolo A, Cossu G and Mavilio $F$ (1998) Muscle regeneration by bone marrow-derived myogenic progenitors. Science 279: 1528-1530. 